\title{
ANALISIS BREAK EVEN POINT USAHA PENGGEMUKAN KAMBING MILIK BAPAK SULTON DESA SIDOREJO KECAMATAN PONGGOK KABUPATEN BLITAR
}

\author{
Aan Jiwo Prasetyo ${ }^{1)}$, Nita Opi Ari Kustanti ${ }^{2)}$, Sri Setyawati ${ }^{2)}$ \\ ${ }^{1)}$ Mahasiswa Program Studi Ilmu Ternak Fakultas Peternakan \\ ${ }^{2)}$ Dosen Program Studi Ilmu Ternak Fakultas Peternakan \\ Universitas Islam Balitar \\ Jl. Majapahit No. 04 Kota Blitar
}

\begin{abstract}
This research formulates one problem hit analisis finishing effort goat on Sulton's Father ranch Sidorejo's Village Ponggok's district Blitar's Regency. Expected by this research can become consideration for cattlemen to take a decision deep fattening's effort management goat. This research is done at Fathers own ranch Sulton lies at Pancir's Orchard Sidorejo's Village Ponggok's district Blitar's Regency. Data is taken from one fattening's period which is 3 months utilize case study and data method at fetching descriptive ala and quantitative.Capital constitutes a number goods, service, and money to start an effort stage. Production cost constitutes all cost that issued by producer to result a goods or service product. Differentiated production cost becomes two kinds which is fixed cost ( fixed cost) and offbalance cost( variable cost ). Immanent cost all cost that don't hinge on outgrows its little production. Cost is not immanent all big cost its little cost hinges on outgrows its little production. Of this research is acquired data total production cost as big as Rp 11.977.323, totaled acceptance as big as Rp 16.105.00 so gets to be gotten by Rp's gains 4.127 .600 about production periods, gain a moon Rp 1.375.000. Mean while BEP is production it is 16.24 and BEP is price it is Rp 598.866. Base data that at gets from research result, can know effort gain zoom finishing goat and gets to be seen by break even point's break even point or dot finishing effort goat with aught.
\end{abstract}

Keyword : Break even point, Fatenning

\section{PENDAHULUAN}

Tujuan mendirikan sebuah perusahaan adalah untuk memperoleh keuntungan untuk kelangsungan hidup. Kemajuan dan perkembangan perusahaan akan membawa akibat bagi pembangunan perusahaan itu sendiri baik positif maupun negatif. Di kalangan perusahaan itu sendiri, perkembangan dan kemajuan dunia usaha telah membawa kearah persaingan yang semakin ketat, sedangkan usaha untuk mencapai laba tak bisa di pisahkan dari masalah penjualan, peningkatan penjualan yang tinggi belumlah berarti mendapatkan laba yang besar(Sarwono B,2002).

Pada hakekatnya setiap perusahaan yang didirikan mempunyai harapan di kemudian hari, misalnya mengharapkan perkembangan yang sangat pesat. Perkembangan perusahaan pada dasarnya menginginkan tercapainya suatu tujuan yaitu memperoleh laba dan menjaga kontinuitas usahanya. Untuk mencapai tujuan-tujuan tersebut tidak semudah membalikkan telapak tangan, karena tiap-tiap perusahaan akan memaksa mereka untuk bersaing keras. Tidak salah bila dikatakan bahwa perusahaan yang mengabaikan persaingan akan terdesak mundur bahkan akan gulung tikar, oleh karena itu perusahaan harus tetap mengikuti perkembangaan di luar agar bisa bertahan, minimal meningkatkan kemampuan bersaing. Perkembangan 
perusahaan adalah setiap perusahaan yang ingin tetap survival (hidup terus) dan sukses, harus berusaha agar dapat selalu berkembang (Riyanto, 2001).

Dari keterangan tersebut di atas dapat di simpulkan bahwa bagi perusahaan-perusahaan survive dan sukses, harus berusaha untuk meningkatkan volume penjualan (omset) yang di capai perusahaan. Pada dasarnya tujuan perusahaan adalah untuk memperoleh laba besar dan kecilnya laba yang akan di capai merupakan ukuran kesuksesan manajemen dalam mengelola perusahaan oleh karena itu manajemen harus mampu merencanakan sekaligus mencapai laba yang besar agar dapat dikatakan sebagai manajemen sukses (Sutama dan Buarsana,2009).

. Setiap perusahaan akan berusaha untuk mendapat laba sebesar atau seoptimal mungkin. Untuk mencapai hal tersebut perusahaan harus memperoleh pendapatan (income) sebesar mungkin, dan menekan biaya (cost) sekecil mungkin. Pendapatan dari perusahaan berasal dari penjualan, hasil penjualan yang di terima perusahaan berasal dari produksi barang dan jasa yang di lakukannya, maka semakin tinggi produktivitas perusahaan semakin besar pendapatan, dan semakin tinggi efisiensi proses produksi, semakin rendah biaya semakin besar laba yang di dapat perusahaan (Noor, 2007).

Biaya menentukan harga jual untuk mencapai tingkat laba yang di kehendaki, harga jual mempengaruhi volume penjualan, sedangkan volume penjualan langsung mempengaruhi volume produksi dan volume produksi mempengaruhi laba. Oleh karena itu dalam perencanaan laba hubungan antara biaya, volume, dan laba memegang peranan yang sangat penting. Hubungan tersebut dapat di ketahui lebih lanjut melalui analis Break Even Point. Sedangkan analisis Break Even point ini sendiri merupakan cara teknik untuk mengetahui hubungan antara volume produksi, volume penjualan, harga jual, biaya tetap, dan biaya variabel, serta rugi dan laba(Mulyono,Subangkit,1998). Dalam usaha penggemukan kambing seperti yang dilakukan Bapak Sulton Desa Sidorejo Kecamatan Ponggok Kabupaten Blitar, analisa break even point cukup menarik untuk diungkap dan diteliti, mengingat dalam peternakan rakyat seperti yang dilakukan Bapak Sulton ini belum pernah dilakukan analisa usaha secara detail dan mendalam.

\section{MATERI DAN METODE PENELITIAN}

Materi yang diambil adalah sebuah peternakan rakyat yaitu usaha penggemukan kambing potong milik Bapak Sulton S.Pd. Usaha peternakan ini yang memiliki populasi ternak 20 ekor kambing jantan dan memiliki manajemen yang terarah serta pengelolaan yang baik.

\section{Metode Penelitian}

Metode yang akan di gunakan dalam pelaksanaan penelitian ini adalah metode studi kasus yang merupakan penelitian yang mendalam mengenai suatu kasus dengan prosedur pemecahan masalah yang diselidiki dengan menggambarkan atau melukiskan (metode deskriptif) keadaan yang tampak terhadap objek atau subjek penelitian berdasarkan fakta-fakta atau sebagaimana adanya (Sutapa,1990).

\section{Analisa Data}

Data penelitian dianalisa secara deskriptif dan kuantitatif. Analisa deskriptif adalah untuk menggambarkan objek penelitian kemudian dianalisa sehingga menjadi data kuantitatif yang menunjukan keadaan yang sebenarnya mengenai objek penelitian (Nawawi,Hadari.2005). Analisa kuantatif adalah salah satu prosedur penelitian yang menghasilkan data dalam bentuk jumlah angka-angka sehinga dapat ditarik kesimpulan atas objek yang diteliti (Anonimous,2009).

\section{HASIL DAN PEMBAHASAN}




\section{Keadaan Umum Peternakan}

Desa Sidorejo Kecamatan Ponggok Kabupaten Blitar merupakan salah satu kawasan yang berada di Kabupaten Blitar bagian utara yang merupakan daerah perbatasan Kabupaten Blitar dengan Kabupaten Kediri, dan berbatasan langsung dengan empat desa yaitu: Sebelah Utara berbatasan dengan Desa Bedali (Kabupaten Kediri), sebelah barat berbatas dengan Desa Gembongan, sebelah selatan berbatas dengan Desa Candi Rejo, dan sebelah Timur berbatas dengan Desa Sumber Asri. Dengan sebagian wilayah merupakan lahan pertanian dengan tanah yang subur, hal ini dapat memudahkan dalam mendapatkan bahan baku pakan atau hijauan pakan ternak yang dibutuhkan dalam pemeliharaan ternak.

Lokasi peternakan berada di Dusun Pancir Desa Sidorejo Kecamatan Ponggok Kabupaten Blitar. Dengan kondisi lingkungan di sekitar lokasi perternakan secara garis besar memang sangat mendukung usaha peternakan. Bapak Sulton pemilik usaha, setelah mengalami kegagalan dalam usaha ayam petelur pada tahun 2000. Dengan didasarkan atas pemikiran secara kritis tentang peluang usaha peternakan, Bapak Sulton berinisiatif untuk memelihara kambing. Pada awalnya Bapak Sulton memelihara beberapa ekor saja, setelah usaha mulai berjalan Bapak Sulton mulai mengembangkan usaha dan memprioritaskan pemeliharaan sistem penggemukan kambing.

Penggemukan kambing yang dilakukan oleh Bapak Sulton ini dilaksanakan dengan begitu intensif. Jadi dari mulai awal sebelum kambing digemukan harus melalui beberapa proses dan tahapan. Tahapan kegiatan yang dilakukan Bapak Sulton seperti pada tabel berikut:

Tabel 1. Proses Kegiatan Penggemukan Kambing

\begin{tabular}{|l|c|}
\hline \multicolumn{1}{|c|}{ Kegiatan } & Waktu \\
\hline Pengadaan bakalan & 1 bulan \\
\hline Proses karantina & 1 minggu \\
\hline Proses penggemukan & 3 bulan \\
\hline Pemasaran & 2 minggu \\
\hline
\end{tabular}

Sumber: Data primer yang diolah(2015)

Pada tabel diatas menunjukan dalam proses tahap pertama, yaitu pengadaan bakalan yang membutuhan waktu 1 bulan karena dalam memilih bakalan yang baik dibutuhkan ketelitian dan kecermaatan, itu dilakukan untuk menghindari terjadinya salah beli yang dapat mengakibatkan kegagalan usaha. Selain itu, memang dibutuhkan waktu untuk mengantisipasi fluktuasi harga kambing dipasaran. Untuk proses adaptasi tidak membutuhkan waktu yang lama karena pada umumnya ternak kambing cukup mudah beradaptasi. Proses pemasaran merupakan faktor penting dalam usaha penggemukan. Karena memiliki banyak teman dan relasi dalam segi pemasaran Bapak Sulton sampai saat ini belum merasa kesulitan, karena pada saat panen sudah ada pembeli yang datang untuk membeli ternak-ternaknya.

Populasi ternak yang digemukan sekarang berjumlah 20 ekor. Ternak kambing yang dijadikan bakalan berasal dari jenis kambing PE pejantan berumur sekitar 8 sampai 24 bulan, yang memiliki tubuh kurus akan tetapi sehat sehingga akan mudah untuk proses pengemukan. Data umur kambing yang digemukan separti pada tabel berikut :

Tabel 2. Data Jumlah dan Umur Kambing

\begin{tabular}{|l|l|c|}
\hline No. & \multicolumn{1}{|c|}{ Umur (bulan) } & Jumlah (ekor) \\
\hline $\mathbf{1}$ & $8-12$ & 5 \\
\hline $\mathbf{2}$ & $13-17$ & 6 \\
\hline $\mathbf{3}$ & $18-22$ & 9 \\
\hline
\end{tabular}




\begin{tabular}{|l|l|c|}
\hline & Jumlah & 20 \\
\hline
\end{tabular}

Sumber: Data primer yang diolah(2015)

Kambing yang digemukan kebanyakan kambing yang sudah berumur tidak terlalu tua dan tidak terlalu muda, ini disebabkan karena pada umur-umur seperti itu kambing memiliki nafsu makan yang tinggi sehingga mudah dalam perbaikan karkasnya. Untuk Harga kambing biasanya tidak dengan penimbangan berat badan, akan tetapi dengan pengamatan bentuk kemudian disesuaikan dengan harga. Penimbangan tidak dilakukan karena kambing diperoleh dari para masyarakat sekitar yang tidak terbiasa dengan penimbangan. Harga bakalan berkisar antara $\mathrm{Rp} 250.000$ sampai $\mathrm{Rp} 400.000$, dengan rata-rata harga per ekor Rp 330.000. Mengenai jumlah rata-rata harga beli kambing dapat dilihat pada lampiran 4. Kambing bakalan diperoleh dari para petani dan pedagang disekitar lokasi peternakan. Akan tetapi tidak jarang Bapak Sulton mencari kambing bakalan keluar daerah, misalnya Srengat, Wates Kediri dan Gandusari.

Lokasi kandang kambing milik Bapak Sulton ini cukup strategis karena terdapat di pedesaan jauh dari keramaian, akan tetapi akses jalan ke lokasi peternakan sangat mudah dijangkau kendaraan. Bapak Sulton memiliki 1 unit kandang dengan ukuran 5 x 10 m dengan kepadatan kandang $2.5 \mathrm{~m}^{2} /$ ekor. Kandang kambing tersebut berupa kandang panggung dengan tiang kandang dari bahan cor, lantai dan dinding kandang dari kayu dan bambu serta atapnya dari bahan asbes.

Mengenai pakan, untuk memperkecil biaya Bapak Sulton sudah berinisistif sejak dari awal untuk menanami sebagian lahan tanah dengan tanaman hijauan pakan ternak seperti ; ruput gajah, kaliandra, lamtoro, dan gamal. Meskipun demikian untuk pakan ternak hijauan yang dimiliki masih belum mencukupi, sehingga sekitar 30\% kebutuhan hijauan masih membeli di pedagang pakan ternak. Selain hijauan Bapak Sulton juga memberikan konsentrat sebagai pakan penguat. Tiap ekor kambing rata-rata diberikan $0.5 \mathrm{~kg}$ konsentrat setiap harinya. Dengan pakan yang diberikan tersebut pertambahan bobot kambing tergolong sangat baik yaitu bertambah antara 0.25 sampai $0.7 \mathrm{~kg}$ per hari.

\section{Modal Usaha}

Modal usaha yang digunakan oleh Bapak Sulton adalah modal pribadi, yaitu modal sisa dari usaha sebelumnya yang mengalami kebangkrutan. Permodalan dalam usaha penggemukan kambing ini terdiri dari modal tetap dan modal kerja. Yang termasuk dalam modal tetap diantaranya adalah modal pendirian kandang dan peralatan. Sedangkan yang termasuk modal kerja atau modal bergerak diantaranya pembelian bibit bakalan, pakan, obat-obatan dan vaksin, serta upah tenaga kerja. Besar modal investasi dan modal kerja Bapak Sulton seperti pada tabel berikut :

\section{Tabel 3. Modal Tetap dan Modal Kerja}

\begin{tabular}{|l|c|c|}
\hline No. & \multicolumn{1}{|c|}{ Modal } & Jumlah \\
\hline $\mathbf{1}$ & Modal tetap & \\
\hline & - Pendirian kandang & Rp 2.771.000 \\
\hline & - Peralatan & Rp 1.565 .000 \\
\hline $\mathbf{2}$ & Modal kerja & \\
\hline & - Pembelian bakalan & Rp 6.600 .000 \\
\hline & - Pakan & Rp 4.050 .000 \\
\hline & - Obat dan vaksin & Rp 150.000 \\
\hline
\end{tabular}




\begin{tabular}{|l|l|c|}
\hline & - Tenaga kerja & Rp 900.000 \\
\hline & Total modal usaha & Rp 16.036 .000 \\
\hline
\end{tabular}

Sumber: Data primer yang diolah(2015)

Dari tabel diatas dapat dilihat modal pendirian kandang sebesar Rp 2.771.000, sedangkan untuk peralatan sebesar Rp 1.565.000. sedangkan modal kerja pembelian bakalan Rp 6.600.000, pembelian pakan Rp 1.350.000 per bulan untuk satu periode produksi berarti sebesar Rp 4.050.000, pembelian obat dan vaksin Rp 150.000 dan upah tenaga kerja $\mathrm{Rp}$ 900.000 per periode produksi.

\section{Biaya Produksi}

Biaya produksi meliputi biaya tetap (fixed cost) dan biaya tidak tetap (variable cost). Biaya tetap adalah biaya yang besar kecilnya tidak dipengaruhi oleh besar kecilnya produksi. Sedangkan biaya tidak tetap adalah biaya yang besar kecilnya dipengaruhi biaya produksi. Dalam usaha pengemukan kambing yang dijalankan oleh Bapak Sulton ini, yang termasuk biaya tetap dan biaya tidak tetap seperti pada tabel berikut :

Tabel 4. Biaya Tetap dan Biaya Tidak Tetap

\begin{tabular}{|c|c|c|}
\hline No & Jenis biaya & Jumlah \\
\hline \multirow[t]{6}{*}{1} & Biaya tetap & \\
\hline & - Penyusutan kandang & $\begin{array}{ll}\mathrm{Rp} & 23.091\end{array}$ \\
\hline & - Penyusutan peralatan & $\begin{array}{ll}\mathrm{Rp} & 27.750\end{array}$ \\
\hline & - Penyusutan sewa tanah & $\mathrm{Rp} \quad 41.600$ \\
\hline & Total biaya tetap per bulan & $\mathrm{Rp} \quad 92.441$ \\
\hline & Tota biaya tetap per periode produksi & $\mathrm{Rp} \quad 277.323$ \\
\hline \multirow[t]{7}{*}{2} & Biaya tidak tetap & \\
\hline & - Pembelian kambing bakalan & Rp 6.600 .000 \\
\hline & - Pakan & $\mathrm{Rp} \quad 4.050 .000$ \\
\hline & - Obat dan vaksin & 150.000 \\
\hline & - Upah tenaga kerja & 900.000 \\
\hline & Total biaya tidak tetap per periode produksi & Rp 11.700 .000 \\
\hline & Total biaya /TC per periode produksi & Rp 11.977 .323 \\
\hline
\end{tabular}

Sumber: Data primer yang diolah(2015)

Dari data diatas dapat dilihat besarnya penyusutan kandang sebesar Rp 23.091 per bulan, biaya penyusutan peralatan Rp 27.750 per bulan, biaya penyusutan sewa tanah $\mathrm{Rp}$ 41.600 per bulan, sehingga total biaya tetap perbulan adalah $\mathrm{Rp} 92.441$ dan biaya tetap per periode produksi adalah $\mathrm{Rp} 277.323$. Sedangkan biaya tidak tetap biaya terdiri dari pembelian kambing bakalan sebesar Rp 6.600.000, pakan per periode sebesar Rp 4.050.000, obat dan vaksin sebesar Rp 150.000, dan biaya tenaga kerja per periode produksi sebesar Rp 900.000, sehingga total biaya tidak tetapnya adalah Rp 11.700.000.

Penerimaan Usaha 
Penerimaan adalah nilai uang yang diterima dari hasil penjualan produk barang atau jasa suatu perusahaan. Penerimaan usaha berasal dari semua penjualan hasil usaha peternakan. Usaha penggemukan kambing potong milik Bapa Sulton ini memiliki beberapa penerimaan usaha, rincian penerimaan dari usaha penggemukan ini seperti pada berikut :

Tabel 5. Penerimaan Usaha

\begin{tabular}{|l|l|c|}
\hline No & \multicolumn{1}{|c|}{ Penerimaan } & Jumlah \\
\hline $\mathbf{1 .}$ & Penjualan ternak & $\mathrm{Rp} 14.750 .000$ \\
$\mathbf{2 .}$ & Penjualan pupuk kandang & $\mathrm{Rp} 1.250 .000$ \\
$\mathbf{3 .}$ & Penjualan sak @ Rp 2.500 x 42 & $\mathrm{Rp} 105.000$ \\
\hline & Total peneriman & $\mathrm{Rp} 16.105 .000$ \\
\hline
\end{tabular}

Dari tabel diatas dapat dilihat bahwa penjualan ternak keseluruhan sebesar Rp 14.750.000, dengan penjualan rata-rata perekor Rp 737.500. Data harga kambing dapat dilihat pada lampiran 7. Penjualan pupuk kandang sebesar Rp 1.250.000, dan penjualan sak sebesar Rp 105.000 sehingga total penerimaannya adalah Rp 16.105.000. penjualan ternak merupakan penerimaan yang paling besar dibandingkan dengan penjualan pupuk kandang dan penjual sak karena hanya sebagai hasil sampingan. Sebagai hasil sampingan pupuk kandang biasanya dijual kepada petani sekitar peternakan, sedangkan sak biasanya dijual ke toko atau para petani yang membeli untuk wadah hasil pertanian.

\section{Keuntungan Usaha/ Rugi-Laba}

Besarnya keuntungan dipengaruhi oleh besarnya usaha. Keuntungan usaha peternakan diperoleh dari pengurangan dari total penerimaan usaha peternakan dengan total biaya produksi. Dari usaha penggemukan yang dilakukan Bapak Sulton, dalam satu periode produksi memperoleh keuntungan seperti pada table berikut :

\section{Tabel 6. Keuntungan}

\begin{tabular}{|l|l|l|}
\hline No & \multicolumn{1}{|c|}{ Keterangan } & \multicolumn{1}{c|}{ Jumlah } \\
\hline $\mathbf{1}$ & Penerimaan & Rp 16.105.000 \\
\hline $\mathbf{2}$ & Biaya Keuntungan & $\mathrm{Rp} \mathrm{11.977.323}$ \\
\hline & \multicolumn{2}{c}{ Rp 4.127.600 } \\
\hline
\end{tabular}

Sumber: Data primer yang diolah(2015)

Dari tabel diatas dapat dilihat keuntungan usaha itu diperoleh dari total penerimaan sebesar Rp 16.105.000 dikurangi biaya total produksi sebesar Rp 11.977.323. Sehingga diperoleh keuntungan sebesar Rp 4.127.600/periode produksi, dan diperoleh keuntungan perbulannya sebesar Rp 1.375.000/bulan.

\section{Break Even Point (BEP)}

Break even point adalah suatu kondisi dimana sebuah usaha tidak mengalami keuntungan ataupun karugian. Break even point terdiri dari dua macam yaitu break even point produksi dan break even point harga. Perhitungan break even point perlu dilakukan oleh sebuah 
perusahaan untuk mengetahui titik impas produksi dan titik impas harga penjualan produkproduknya. Sehingga sebuah perusahaan dapat menentukan harga yang pantas untuk sebuah produknya.

Setelah dilakukan perhitungan break even point, break even point produksi dari usaha yang dijalankan Bapak Sulton, dapat dilihat pada tabel berikut ini:

\section{Tabel 7. BEP Harga}

\begin{tabular}{|l|l|l|}
\hline No & \multicolumn{1}{|c|}{ Keterangan } & \multicolumn{1}{c|}{ Jumlah } \\
\hline $\mathbf{1}$ & Total biaya & Rp 11.977 .323 \\
\hline $\mathbf{2}$ & Total produksi & 20 ekor \\
\hline & BEP harga & Rp 598.866 \\
\hline
\end{tabular}

Sumber: Data primer yang diolah(2015)

Dari tabel di atas dapat dilihat bahwa diperoleh BEP harga sebesar Rp 598.886 dari pembagian antara biaya total dan total produksi. Jadi usaha Bapak Sulton akan menerima titik impas harga jika kambing dijual dengan harga sekitar Rp 598.800/ekor. Sedangkan untuk break even point (BEP) dari usaha ini dapat dilihat pada tabel berikut ini:

Tabel 8. BEP Produksi

\begin{tabular}{|l|l|c|}
\hline No & \multicolumn{1}{|c|}{ Keterangan } & Jumlah \\
\hline 1 & Total biaya & $\mathrm{Rp} \mathrm{11.977.323}$ \\
\hline 2 & Harga penjualan & $\mathrm{Rp} \quad 737.500$ \\
\hline & \multicolumn{1}{|c|}{ BEP produksi } & 16.24 \\
\hline
\end{tabular}

Sumber: Data primer yang diolah(2015)

Dari tabel di atas dapat dilihat BEP produksinya 16.24, yaitu dari hasil bagi antara biaya total produksi dengan harga jual kambing per ekor. Jadi usaha bapak Sulton akan menerima titik impas produksi jika Bapak Sulton hanya bisa menjual 16 ekor saja dari jumlah total yang diproduksi.

\section{KESIMPULAN DAN SARAN}

\section{Kesimpulan}

Berdasarkan hasil penelitian dapat ditarik beberapa kesimpulan diantaranya :

a. Setelah dilakukannya analisa usaha penggemukan kambing pada peternakan Bapak Sulton dapat terlihat dengan penerimaan sebesar Rp 16.105.000 dan dengan total biaya produksi (total cost) sebesar Rp 11.977.323 usaha penggemukan milik Bapak Sulton ini dapat memperoleh keuntungan sebesar Rp 4.127.600/periode produksi atau Rp 1.375.600/bulan.

b. Dari analisa BEP produksi yang dilakukan, usaha penggemukan kambing Bapak Sulton ini adalah 16,24, jadi bisa dikatakan jika Bapak Sulton hanya dapat menjual 16 ekor kambing dari jumlah total kambing yang digemukan maka Bapak Sulton tidak akan menerima untung atau rugi. Sedangkan BEP harganya adalah Rp 598.886, jadi jika Bapak Sulton menjual kambingnya dengan harga Rp 598.886 per ekor maka bapak Sulton tidak akan mendapat keuntungan maupun kerugian.

\section{Saran}

Berdasarkan penelitian yang dilakukan saran yang dapat diajukan diantaranya :

a. Dalam sebuah usaha khususnya usaha peternakan, analisis usaha sangat perlu dilakukan. Analisis break even point dilakukan unutuk mengetahui titik impas harga 
dan produksi. Sehingga sebuah perusahaan dapat menentukan harga yang pantas untuk sebuah produknya.

b. Apabila ingin mengetahui efisiensi penggunaan modal secara maksimal sebaiknya peternak mengunakan analisis usaha terlebih dahulu, sehingga usaha yang dijalankan akan berjalan secara baik dan akan menghasilkan pemasukan (in come) yang baik pula.

\section{DAFTAR PUSTAKA}

Anonimous, 2000. Pengembangan Peternakan Kambing. Dirjen Bina Produsi Peternakan ,2008. Informasi Teknis Peternakan dan Konsumsi Produk Peternakan,http://www.Informasi Teknis Peternakan.co.id/2008/11/ html. diakses pada tanggal 14 April 2015.

2009. Usaha Peternakan Perencanaan Usaha, Analisis, dan Pengelolaan. Direktorat Bina Usaha Tani Ternak dan Pengolaha Hasil Ternak, Jawa Timur. 2009. Pedoman Budidaya Beternak Sapi Potong. Tim Karya Tani Madiri. CV Nuansa Aulia. Bandung.

,2009. Metode penelitian Kuantitatif. http://www..co.id/2009/23/ html. diakses pada tanggal 14 April 2015.

2010. Pedoman Beternak Kambing. CV Nuansa Aulia. Badung.

,2010. Manajemen Pemeliharaan Kambing PE. http://www.cpssss.org/web/home/propinsi/prop/jawa+Timur. Diakses tanggal 19 November 2014.

,(2010). Petunjuk Praktis Menggemukan Kambing, Domba Dan Sapi. Agromedia. Jakarta.

Hardjo Subrota dan Wartomo,1994. Aplikasi Pemuliaan Ternak di Lapangan. Grasindo. Jakarta.

Hernanto, F. 1993. Ilmu Usaha Tani. Cetakan Ketiga. Penebar Swadaya. Jakarta.

Mubyarto,1998. Pengatar Ekonomi Pertanian. LP3ES. Jakarta Mulyono, Subangkit, 1998. Teknik Pembibitan Kambing dan Domba. Penebar Swadaya . Jakarta.

Mulyono S dan Sarwono,2009. Penggemukan Kambing Potong. Penebar Swadaya.Jakarta.

Nawawi, Hadari.2005. Metodelogi Penelitian Bidang Sosial. Universitas Gadjah Mada. Yogyakarta.

Niti Semito,A.S,1984. Pembelanjaan Perusahaan. Ghalia Indonesia. Jakarta. 
Noegroho,N.A,1991. Ilmu Usaha Peternakan. Proram Studi Sosisal Ekonomi. Fakultas Peternakan. Universitas Brawijaya. Malang.

Noor,A.2007. Analisis Break Even Point. Yayasan Penerbit Gadjah Mada. Yogyakarta

Riyanto.B,1993. Pembelanjaan Perusahaan. Yayasan Badan Penerbit. Yogyakarta.

Sarwono B,2002. Beternak Kambing Unggul. Penebar Swadaya. Jakarta.

Sugeng,sudarmono,2009. Penggemukan Kambing dan Domba. Penebar Swadaya. Jakarta Sutama dad Buarsana, 2009. Panduan Lengkap Beternak Kambing dan Domba. Penebar Swadaya. Jakarta.

Sutapa. 1990. Upaya Pelestarian Plasma Nutfah Hewani Ternak Kambing Kacang, $\quad$ Bogor: Komisi Pelestarian Plasma Nutfah Nasional.

Sutama dan Budiarsana,2009.Panduan Lengkap Beternak Kambing dan Domba. Penebar Swadaya. Jakarta. 